\title{
Community pharmacy: an untapped patient data resource
}

\section{David John Wright Michael James Twigg}

School of Pharmacy, University of East Anglia, Norwich, UK

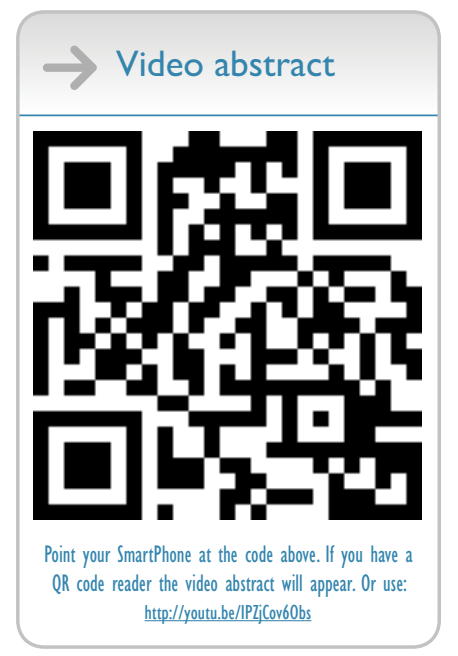

Correspondence: David John Wright School of Pharmacy, University of East Anglia, Earlham Road, Norwich, NR4 7T], UK

Email d.j.wright@uea.ac.uk
This article was published in the following Dove Press journal:

Integrated Pharmacy Research and Practice

7 March 2016

Number of times this article has been viewed

Abstract: As community pharmacy services become more patient centered, they will be increasingly reliant on access to good quality patient information. This review describes how the information that is currently available in community pharmacies can be used to enhance service delivery and patient care. With integration of community pharmacy and medical practice records on the horizon, the opportunities this will provide are also considered. The community pharmacy held patient medication record, which is the central information repository and has been used to identify non-adherence, prompts the pharmacist to clinically review prescriptions, identify patients for additional services, and identify those patients at greater risk of adverse drug events. While active recording of patient consultations for treatment over the counter may improve the quality of consultations and information held, the lost benefits of anonymity afforded by community pharmacies need to be considered. Recording of pharmacy staff activities enables the workload to be monitored, remuneration to be justified, critical incidents to be learned from, but is not routine practice. Centralization of records between community pharmacies enables practices to be compared and consistent problems to be identified. By integrating pharmacy and medical practice records, patient behavior with respect to medicines can be more closely monitored and should prevent duplication of effort. When using patient information stored in a community pharmacy, it is, however, important to consider the reason why the information was recorded in the first instance and whether it is appropriate to use it for a different purpose without additional patient consent. Currently, community pharmacies have access to large amounts of information, which, if stored and used appropriately, can significantly enhance the quality of provided services and patient care. Integrating the records increases opportunities to enhance patient care yet further. While community pharmacies have significant amounts of information available to them, this is frequently untapped.

Keywords: information, patient data, patient medication records, community pharmacy, patient services, primary care

\section{Introduction}

A recent vision for community pharmacy developed by 14 experts from eight different countries was of increased provision of patient-centered care facilitated by the development of new technology, including information technology-based documentation and access to shared patient data. ${ }^{1}$ However, it could be argued that even without this new technology, the community pharmacy already has significant amounts of data which if obtained, stored, and used correctly could assist in the provision of enhanced patient care. This review provides an overview of the different ways in which community pharmacy data have been used to date and could be used in the future. In reviewing 
the literature related to this subject, the reader will see how information, which is currently held, is in itself an untapped resource.

\section{Patient medication records}

Patient medication records held in community pharmacies, which store patient information and the history of medicine supplies made from the pharmacy are now ubiquitous in western health. Such systems when used in their most basic format enable the pharmacist to identify interactions when new medicines are prescribed, check the appropriateness of over-the-counter medicine requests, and are used to facilitate the temporary supply of medicines, which the patient requires when they have been unable to access them in a timely manner from their general practitioner (GP). A more recent use of the basic patient medication record has been to identify the newly prescribed ${ }^{2,3}$ and regular medicines ${ }^{4}$ to enable pharmacists to provide advice to patients as a remunerated service. All of these activities rely on either the patient regularly using the same pharmacy or pharmacies being linked up to enable patients (and data) to transfer between them. With such large numbers of medicine-related errors occurring when patients transfer into hospital, community pharmacy held patient medication records have also been successfully used to ensure that medicines are correctly supplied and administered on admission to hospital as part of the medicines reconciliation process. ${ }^{5}$

Researchers in Australia have recently used patient medication records to insert a prompt for the community pharmacist to question the appropriateness of a prescription for a high-dose proton pump inhibitor. This simple decision support aid, that is relatively easy to include within patient medication recording systems, resulted in reductions in prescribing cost and improvements in prescribing quality. ${ }^{6}$ The routine collection of medicines from the community pharmacy provides numerous opportunities to review prescribing and confirm its appropriateness through interaction with the patient. The information held within the pharmacy is central to this and provides the opportunity and support for brief interventions to optimize prescribing, which may be worthy of remuneration. However, it is important for patient medication records to be accurate and well maintained as this enables new medicines to be correctly identified and prevents unnecessary future interventions if the appropriateness of therapy has previously been questioned and confirmed.

While most pharmacy systems will enable large amounts of patient-specific data to be stored, the pharmacist frequently does not request or record information beyond that required for routine dispensing, eg, allergies or medical conditions. ${ }^{7}$ Possible reasons for this include a lack of time to collect and record the data and patients requiring an efficient service, which is not delayed by answering numerous additional questions. Therefore, the question is whether the benefits obtained from maintaining more complex records justify the extra time taken to complete them. Routinely recording allergies and patient's medical conditions would enable the appropriateness of patients for certain services to be quickly determined and would remove the need for guessing the patient's conditions based on their medicines. At the very least, community pharmacists can use their patient medication records to record approaches for additional services and patient willingness to participate to prevent others from duplicating the offer at a later date.

Another use of the patient medication record could be to identify patients who are not taking their medicines as prescribed. Non-adherence to prescribed therapy is believed to represent a significant cost to the society due to both wastage of medicines and reduced patient outcomes. ${ }^{8}$ Unfortunately, patient adherence is prone to reactivity bias, and the fact that as soon as it is measured and the patient is aware of this observation, it is likely to change. Consequently, effective approaches to identify non-adherence, which do not affect patient behavior, are required. Researchers have shown that it is possible to identify potential non-adherence through review of community pharmacy patient medication records and assuming that noncollection of regular prescriptions is related to nonadherence, ${ }^{9}$ thus providing an opportunity for pharmacists to intervene and support the patients with their medicines to be taken in a timely manner.

The routine recording of prescription supply can, therefore, be used to increase the sensitivity and specificity of screening services and, therefore, cost-effectiveness of the process. The receipt of regular prescriptions for the treatment of hypertension has been used to identify patients at risk of more specific conditions such as hypercholesterolemia ${ }^{10}$ and has demonstrated potential in the case of identifying patients at risk of diabetes. ${ }^{11}$

In addition to the provision of relatively brief interventions for the purposes of improving public health, the management of chronic illness is seen as central to the future of community pharmacy. Consequently, patient medication records have been used to identify patients who may benefit from chronic disease support or interventions to optimize medication. In one study designed to improve management of chronic obstructive pulmonary disease, routine supply of inhaler therapy was used to identify potentially suitable 
patients thereby focusing recruitment, ${ }^{12}$ while in another, the regular receipt of four or more medicines was used as a proxy for risk from adverse drug events..$^{13}$

However, in terms of appropriately identifying and supporting patients, the main information source that is frequently untapped within the pharmacy are the patients themselves. They carry a wealth of information regarding their medicine-taking behaviors, beliefs about medicines, previous medication, and social history. While such information is obtained in all other health care settings, this is not routine practice within the community pharmacy. However, increasingly, short questionnaires are being used to enable risk identification for public health intervention,,${ }^{14}$ to inform the pharmacist about patient's medicines taking and tailor their intervention accordingly, ${ }^{12}$ and, when combined with the patient medication record, to determine the need for drug-related intervention. ${ }^{15}$

\section{Over-the-counter sales}

One area of "information" that is currently available within community pharmacies but not routinely recorded as patientrelated data is individual purchases of medicines over the counter. The regular purchase of medicines for the treatment of cough has successfully been used to identify patients who may be at risk of chronic obstructive pulmonary disease. ${ }^{16}$ Similar approaches could theoretically be used for screening conditions such as celiac disease when patients purchase medicines for the treatment of diarrhea, or diabetes with frequent purchases of anti-fungal treatments.

It has been suggested that recording patient purchases would not only deter abuse commonly seen with over-thecounter medicines ${ }^{17}$ but also enable its identification. ${ }^{17,18} \mathrm{By}$ standardizing the questions asked, which should occur as a result of recording the consultation, drug-related problems would be more consistently identified ${ }^{19}$ and diagnosis would be improved. ${ }^{20}$

While such a change in practice may improve patient care, it would affect the cost of service delivery and possible patient satisfaction if they want to just make a simple purchase. Furthermore, the anonymity afforded by community pharmacies and used to reduce barriers to the purchase of emergency contraception and chlamydia screening would be lost. The centralization of patient records and ability for patients to provide access and make records at their behest may, however, address this, as patients can decide when they want medicine purchases to be recorded and checked by the pharmacist against their current records. Requests for medicines liable to abuse where the patient does not request inclusion into their patient record may prompt the pharmacist or pharmacy staff to consider whether anonymity is being used to inappropriately procure such medicines.

\section{General community pharmacy information}

While information technology systems are central to the provision of medicine-based services, ${ }^{21,22}$ recording the drug-related problems and actions to address them is also important as it enables the pharmacist to plan their activities and monitor the outcomes. ${ }^{23}$ The routine recording of pharmacist interventions also enables frequently occurring prescription-related errors to be identified and fed back to the prescriber to improve patient care. ${ }^{24}$

To describe community pharmacist activities with respect to certain conditions, survey methods and interviews are frequently used. ${ }^{25-27}$ However, survey methods rely on memory recall and are prone to social desirability bias. A more accurate picture would be obtained if community pharmacists accurately recorded their drug-related activities contemporaneously. Not only would this information enable differences in practice between pharmacists and community pharmacies to be identified and quantified, it would also provide justification to service purchasers for the remuneration received for services that are currently nontangible. Such a system has been introduced and tested in Australia and shown to improve the understanding of exactly what pharmacists do. ${ }^{28}$ Similarly, a national database to record community pharmacist interventions has been set up in the UK to enable community pharmacists to obtain reimbursement for services and update medical practice records automatically with the information regarding community pharmacist activities. ${ }^{29}$ This database has been successfully used for the evaluation of new community pharmacy-based services. ${ }^{12,13}$

Workload sampling is an approach where additional data regarding pharmacist and staff activities has been used to review and improve workflow, and hence inform the delivery of patient services. ${ }^{30-32}$ However, data regarding practice activities are only useful when the data can be used to compare between pharmacies to enable the differences to be identified.

Routine recording of near-miss events or errors within the pharmacy can also be used by the pharmacy to improve patient safety through the use of critical incident analysis. ${ }^{33}$ While medication errors remain illegal in some countries, ${ }^{34}$ this information is frequently not recorded. Due to the limited number of serious errors that occur and incomplete recording of near-miss events, this information is more useful when it is stored in a centralized database and consequently patterns 
emerge, which enable identification of strategies to prevent future occurrence. ${ }^{33}$

Similarly, centralization of prescription reclaim information, which is naturally occurring as a result of electronic prescribing, ${ }^{35}$ enables the costs of medicines from different suppliers to be compared. Using such an approach, researchers in the USA have shown that medicines supplied from Internet pharmacies are less expensive than that from retail pharmacies. ${ }^{36}$ Centralized records have also enabled the identification of falsified prescriptions. ${ }^{26}$

\section{Integration of patient records}

Integration of patient records can and is occurring at various levels. First, and perhaps most simply, is that between community pharmacies who use the same dispensary-based software. Linking the community pharmacy records enables patient's medicine-related behavior to be more accurately recorded as many pharmacies will have incomplete records where patients have chosen another community pharmacy for receipt of a supply of medicines. Such an approach is believed to provide rich medicines utilization data, which can be used for research purposes. ${ }^{37}$ Geographic Information Systems technology that is used to create maps of patient activity has been used to analyze linked community pharmacy information and been able to identify variation in local use of prescription medicines, at both individual and population levels. ${ }^{38}$ The capture of medication-related behavior enables questions to be asked regarding variation in service provision at a population level and to obtain more accurate pictures of individual patient behavior. This additional information can then be used to tailor interventions both to the local populations and individual patients.

Linking the pharmacy and GP records, which is technologically and professionally more problematic, ${ }^{39}$ provides additional opportunities for medicines utilization research. GP records state what was prescribed, provided it was entered electronically, while pharmacist records state what was actually collected. Therefore, linking the community pharmacy and GP databases enables a more accurate and complete picture of drug utilization to be obtained. ${ }^{40}$ The prescriber will have a more accurate picture of patient's medicine-taking behavior available to them when authorizing new prescriptions and considering increasing dosages in light of apparent therapeutic failure, which may actually be non-adherence. The pharmacist will additionally be able to confirm whether prescriptions have been authorized and at what dose and use this information to support patients who present without their medicines requiring additional supplies in an emergency.

While the integration of such records between different health care professionals should prevent the patient from being asked duplicate questions and provide more information to the pharmacist when deciding whether to offer a new service to a patient, it may also increase pressure on the pharmacist to ensure that records are complete and up to date. Qualitative research to determine community pharmacist views on the integration of records between themselves and GPs identified concerns regarding exactly what they would not be expected to record with a request for some flexibility within this ${ }^{39}$ as their entries would be available for other health care professionals to view.

Finally, with the increasing use of point-of-care testing within community pharmacies, ${ }^{10,41}$ the risk of duplicated effort by community pharmacists and GPs, and consequently, an ability to relay test results to the patient's primary care physician also becomes more important. This avoidance of duplication has also been identified with regard to medicine use reviews in the UK, with GPs stating that as a reason for their reluctance to engage with pharmacy-provided services. ${ }^{42,43}$

\section{Big Brother}

As databases become more integrated and powerful, the ability to monitor patient behavior is increased. If this progress is not carefully managed, we potentially move closer to Big Brother seen in George Orwell's 1984, particularly when the services we want to provide are those that the society has decided are for the greater good but do not align with individual lifestyle choices.

While supermarkets already monitor our purchases and provide coupons and offers that are individualized to our preferences, they do this through loyalty cards, which we have signed up for, to know that information would be used in this manner. Similarly, while the software used in medical practices, where GP records are held, is frequently designed to monitor the frequency of our prescription requests and can be used by GPs when discussing medicines, patients have usually registered with the medical practice to allow personal information to be stored and monitored and do this on the assumption that all information is being used for their benefit. Occasionally, medical practices will approach patients on behalf of researchers to determine whether they would like to be involved in a study related to their demographics or medical condition, but do this in the knowledge that the research may be of benefit; the research team have not had prior access 
to patients' information, and they have to provide consent to participate before any information is released to them.

Community pharmacists obtain patient information through the supply of medicines either by prescription or over the counter. In the UK at least, patients are not required to register with their community pharmacy or provide consent for their prescription information to be stored. The law allows this information to be stored without consent provided that it is used for limited, specifically stated purposes ${ }^{44}$ Consequently, patients visiting community pharmacies may not be so comfortable if they knew that community pharmacists were using such information to determine which additional remunerated services to provide to them or that we were actively sharing information with other health care professionals to obtain a more accurate picture of their behavior.

Therefore, whenever we choose to use patient information held within community pharmacies to extend or enhance the range of services offered, it is important that we consider the patient's perspective and that we obtain consent to use the information for other purposes where appropriate.

\section{Conclusion}

Information stored within community pharmacy patient medication records routinely enhances patient care through the ability to identify interactions between new medicines and existing therapy and by supporting the provision of medicines to patients who have failed to obtain their medicines in a timely manner. However, it provides a multitude of opportunities to further enhance patient care, many of which are currently untapped either due to a lack of resources to fund services based upon them or due to a lack of awareness of how the information could be more usefully used.

Information held within patient medication records can be used to identify potential patient non-adherence, identify patients who may benefit from public health interventions, and facilitate the identification of patients for chronic illness management. It can be used to prompt for medication review when high-risk medicines or dosages are prescribed and be used for routine monitoring of patients. The information held within patient medication records can also be used to support the medicines reconciliation process when patients transfer into hospital.

The usefulness of such information is enhanced further when records between pharmacies are combined, and then, again when these are linked to medical practices. However, many new services can be provided using the information available in individual pharmacies that have a regular patient base. However, the quality of information held within patient medication records will affect the efficiency of new service provision as the more accurate and complete it is the more focused approaches to patients can be and less unnecessary duplication of effort should occur.

Information in community pharmacies regarding nearmiss and actual errors, if recorded and collated, can be used to improve local practices and patient safety. Similarly, actively recording pharmacist and staff activities can be used to describe working practices in order to enable their review and optimization of service delivery. Recording all medicinerelated activities is helpful to enable feedback to prescribers to prevent similar errors and demonstrate exactly what pharmacists do and, therefore, justify their professional role.

The purchase of medicines over the counter is currently an area where there is a lot of potentially useful information that could be collated either to identify patients who may benefit from screening or public health interventions or to identify abuse, which requires greater support. Empowering the patients to decide when such purchases can be recorded should increase the wealth of information available regarding patient self-medication and enable those patients choosing not to record information to be identified.

The patient is a source of information that routinely enters a community pharmacy, and this has been tapped by the use of short questionnaires to enable risk assessment to be performed and inform interventions to enable them to be tailored to the individual patient.

Integration of patient records between different practitioners will enable a more accurate picture of medicines utilization and cost to be obtained, thus providing opportunities for tailoring services both geographically and individually. While linking of records increases the quality of information available, its eventual effectiveness will depend on whether individuals have time and sufficient incentives to access and use the collated data.

When considering using patient information for purposes for which it was not intended, ie, using prescription supply information to identify patients possibly in need of a public health intervention, we need, however, to think carefully about the appropriateness of this, not only within the confines of local legislative frameworks for data management, but also from the perspective of the patient who may not be aware that their data are being used in this manner. Information held within community pharmacies is untapped as it currently stands; however, tapping it may, in certain circumstances, require a review of how the data were collected in the first 
place and what the patient was told the information would be used for.

\section{Disclosure}

The authors routinely undertake consultancy work for private companies and charities to undertake independent evaluations of novel community pharmacy-based services. The authors report no other conflicts of interest in this work.

\section{References}

1. Westerling AM, Haikala V, Airaksinen M. The role of information technology in the development of community pharmacy services: visions and strategic views of international experts. Res Social Adm Pharm. 2011;7(4):430-437.

2. Evans CD, Eurich DT, Taylor JG, Remillard AJ, Shevchuk YM, Blackburn DF. A pragmatic cluster randomized trial evaluating the impact of a community pharmacy intervention on statin adherence: rationale and design of the community pharmacy assisting in total cardiovascular health (CPATCH) study. Trials. 2010;11:76.

3. Boyd M, Waring J, Barber N, et al. Protocol for the New Medicine Service Study: a randomized controlled trial and economic evaluation with qualitative appraisal comparing the effectiveness and cost effectiveness of the New Medicine Service in community pharmacies in England. Trials. 2013;14(1):411.

4. Portlock J, Holden M, Patel S. A community pharmacy asthma MUR project in Hampshire and the Isle of Wight. Pharm J. 2009; 282(7537):109-112.

5. Tompson AJ, Peterson GM, Jackson SL, Hughes JD, Raymond K. Utilizing community pharmacy dispensing records to disclose errors in hospital admission drug charts. Int J Clin Pharmacol Ther. 2012;50(9):639-646.

6. Curtain C, Peterson GM, Tenni P, Bindoff IK, Williams M. Outcomes of a decision support prompt in community pharmacy-dispensing software to promote step-down of proton pump inhibitor therapy. $\mathrm{Br} J$ Clin Pharmacol. 2011;71(5):780-784.

7. Floor-Schreudering A, De Smet PA, Buurma H, Egberts AC, Bouvy ML. Documentation quality in community pharmacy: completeness of electronic patient records after patients' first visits. Ann Pharmacother. 2009;43(11):1787-1794.

8. World Health Organization. Adherence to Long Term Therapies: Evidence for Action. Geneva: World Health Organization; 2003.

9. Feehan M, Ranker L, Durante R, et al. Adherence to controller asthma medications: 6-month prevalence across a US community pharmacy chain. J Clin Pharm Ther. Epub 2015 Aug 20.

10. Gardner SF, Skelton DR, Rollins SD, Hastings JK. Community pharmacy data bases to identify patients at high risk for hypercholesterolemia. Pharmacotherapy. 1995;15(3):292-296.

11. Simoens S, De Coster S, Dethier M, Lenie J, Meuwissen P, Laekeman G. Cardiovascular drug use prior to diagnosis of diabetes: a pilot study in community pharmacy. Int J Pharm Pract. 2009;17(2):127-129.

12. Wright D, Twigg M, Barton G, Thornley T, Kerr C. An evaluation of a multi-site community pharmacy-based chronic obstructive pulmonary disease support service. Int J Pharm Pract. 2015;23(1):36-43.

13. Twigg MJ, Wright D, Barton GR, Thornley T, Kerr C. The four or more medicines (FOMM) support service: results from an evaluation of a new community pharmacy service aimed at over-65s. Int J Pharm Pract. Epub 2015 Apr 6.

14. Twigg MJ, Wright DJ, Thornley T, Haynes L. Community pharmacy type 2 diabetes risk assessment: demographics and risk results. Int J Pharm Pract. 2015;23(1):80-82.

15. Pammett RT, Blackburn D, Taylor J, et al. Evaluation of a community pharmacy-based screening questionnaire to identify patients at risk for drug therapy problems. Pharmacotherapy. 2015;35(9):881-886.
16. Wright $\mathrm{D}$, Twigg M, Thornley T. Chronic obstructive pulmonary disease case finding by community pharmacists: a potential cost-effective public health intervention. Int J Pharm Pract. 2015;23(1):83-85.

17. Fleming GF, McElnay JC, Hughes CM. Development of a community pharmacy-based model to identify and treat OTC drug abuse/misuse: a pilot study. Pharm World Sci. 2004;26(5):282-288.

18. Cooper R. Surveillance and uncertainty: community pharmacy responses to over the counter medicine abuse. Health Soc Care Community. 2013;21(3):254-262.

19. Eickhoff C, Hammerlein A, Griese N, Schulz M. Nature and frequency of drug-related problems in self-medication (over-the-counter drugs) in daily community pharmacy practice in Germany. Pharmacoepidemiol Drug Saf. 2012;21(3):254-260.

20. Ishii M, Nagamine A, Kimura Y, et al. [Is a migraine screener useful for pharmacists in community pharmacy to distinguish patients with migraine?]. Yakugaku Zasshi. 2010;130(6):881-887.

21. Amruso NA. Ability of clinical pharmacists in a community pharmacy setting to manage anticoagulation therapy. J Am Pharm Assoc (2003). 2004;44(4):467-471.

22. Negru DS, Diaconescu M, Petculescu AM, Bild V. Community pharmacy - ideal location to screen and monitor hypertensive patients. Rev Med Chir Soc Med Nat Iasi. 2010;114(3):904-909.

23. American Pharmacists Association; National Association of Chain Drug Stores Foundation. Medication therapy management in community pharmacy practice: core elements of an MTM service (version 1.0). J Am Pharm Assoc (2003). 2005;45(5):573-579.

24. Martinez Sanchez A, Campos RM. Detection of prescribing related problems at the community pharmacy. Int J Clin Pharm. 2011;33(1):66-69.

25. Ise Y, Morita T, Maehori N, Kutsuwa M, Shiokawa M, Kizawa Y. Role of the community pharmacy in palliative care: a nationwide survey in Japan. J Palliat Med. 2010;13(6):733-737.

26. Lapeyre-Mestre M, Gony M, Carvajal A, et al. A European community pharmacy-based survey to investigate patterns of prescription fraud through identification of falsified prescriptions. Eur Addict Res. 2014;20(4):174-182.

27. Maher JH, Lowe J, Hughes R. Community pharmacy as a setting for public health nutrition action: Australian nutritionists' perspectives. Public Health Nutr. 2015;18(10):1864-1872.

28. Williams M, Peterson GM, Tenni PC, Bindoff IK, Stafford AC. DOCUMENT: a system for classifying drug-related problems in community pharmacy. Int J Clin Pharm. 2012;34(1):43-52.

29. PSNC [homepage on the Internet]. PSNC [cited October 14, 2015]. Available from: https://pharmoutcomes.org/pharmoutcomes/.Accessed February 5, 2016.

30. Boyd R, Parker WA, Yung DK. Characterization of pharmacy workload and pharmacist activities in a Canadian community pharmacy. Contemp Pharm Pract. 1982;5(4):219-225.

31. Boyle TA, Scobie AC, MacKinnon NJ, Mahaffey T. Implications of process characteristics on quality-related event reporting in community pharmacy. Res Social Adm Pharm. 2012;8(1):76-86.

32. McCann L, Hughes CM, Adair CG. A self-reported work-sampling study in community pharmacy practice: a 2009 update. Pharm World Sci. 2010;32(4):536-543.

33. Phipps DL, Tam WV, Ashcroft DM. Integrating data from the UK national reporting and learning system with work domain analysis to understand patient safety incidents in community pharmacy. J Patient Saf. Epub 2014 Feb 27.

34. CPS [webpage on the Internet]. CPS Publishes Guidance on Prosecuting Medicines Act Offences Where a Dispensing Error Has Occurred [cited October 14, 2015]. Available from: http:/www.cps.gov.uk/news/ latest_news/cps_publishes_guidance_on_prosecuting_medicines_ act_offences_where_a_dispensing_error_has_occurred_/. Accessed February 5, 2016.

35. Harvey J, Avery AJ, Barber N. A qualitative study of community pharmacy perceptions of the Electronic Prescriptions Service in England. Int J Pharm Pract. 2014;22(6):440-444. 
36. Clark BE, Siracuse MV, Garis RI. A comparison of mail-service and retail community pharmacy claims in 5 prescription benefit plans. Res Social Adm Pharm. 2009;5(2):133-142.

37. Horsburgh S, Norris P, Becket G, et al. The equity in prescription medicines use study: using community pharmacy databases to study medicines utilisation. J Biomed Inform. 2010;43(6):982-987.

38. Ryan K, Norris P, Becket G. Capturing data on medicines usage: the potential of community pharmacy databases. $N Z \mathrm{Med} J$. 2005;118(1223):U1677.

39. Mooranian A, Emmerton L, Hattingh L. The introduction of the national e-health record into Australian community pharmacy practice: pharmacists' perceptions. Int J Pharm Pract. 2013;21(6):405-412.

40. Florentinus SR, Souverein PC, Griens FA, Groenewegen PP, Leufkens HG, Heerdink ER. Linking community pharmacy dispensing data to prescribing data of general practitioners. BMC Med Inform Decis Mak. 2006;6:18.
41. Gubbins PO, Klepser ME, Dering-Anderson AM, et al. Point-ofcare testing for infectious diseases: opportunities, barriers, and considerations in community pharmacy. J Am Pharm Assoc (2003). 2014;54(2):163-171.

42. Wilcock M, Harding G. General practitioners' perceptions of medicines use reviews by pharmacists. Pharm J. 2007;279:501-503.

43. Bryant L, Coster G, Gamble G, McCormick R. General practitioners' and pharmacists' perceptions of the role of community pharmacists in delivering clinical services. Res Social Adm Pharm. 2009;5:347-362.

44. GOV.UK [webpage on the Internet]. Data Protection Act Principles [cited October 29, 2015]. Available from: https://www.gov.uk/dataprotection/the-data-protection-act. Accessed February 5, 2016.
Integrated Pharmacy Research and Practice

\section{Publish your work in this journal}

Integrated Pharmacy Research and Practice is an international, peer-reviewed, open access, online journal, publishing original research, reports, reviews and commentaries on all areas of academic and professional pharmacy practice. This journal aims to represent the academic output of pharmacists and pharmacy practice with particular focus on integrated care. All papers are carefully

\section{Dovepress}

peer reviewed to ensure the highest standards as well as ensuring that we are informing and stimulating pharmaceutical professionals. The manuscript management system is completely online and includes a very quick and fair peer-review system, which is all easy to use. Visit http://www.dovepress.com/ testimonials.php to read real quotes from published authors.

Submit your manuscript here: http://www.dovepress.com/integrated-pharmacy-research-and-practice-journal 